\title{
Study on a Multilevel Fuzzy Evaluation Method for Reliability Allocation
}

\author{
Xuehong He, Yuxiang Du and Liyang Xie \\ School of mechanical engineering and automation, Northeastern University, Shenyang 110819
}

\begin{abstract}
Reliability allocation is a significant part of reliability design. There are a number of factors that affect the reliability. A new method of reliability allocation is proposed based on the fuzzy theory and AHP method. The core of this method is to introduce the improved AHP method to determine the weight of factors, and the Fuzzy evaluation allocation method is used for comprehensive evaluation. Finally, an engineering example is given to illustrate its application and its simplicity and effectiveness.
\end{abstract}

Keywords-aeroengine; reliability allocation; fuzzy theory; the improved AHP

\section{INTRODUCTION}

Reliability allocation is essentially an engineering decision process, which is a comprehensive measure of optimization and an important component step of system reliability design. Considering the reliability index specified in the task book, reliability allocation is assigned to the subsystems and components from top to bottom according to certain rules ${ }^{[1,2]}$.

For reliability allocation problem of complex systems, it is difficult to assign the reliability accurately and scientifically using conventional allocation techniques. At present, common reliability allocation methods include fuzzy evaluation allocation method, AHP and so on ${ }^{[3,4]}$. The comment set is often fuzzy when the relationship of the distribution target and the reliability influence factor is established, so fuzzy evaluation allocation method should be adopted. The index weight is very important using the fuzzy evaluation allocation method. The weight of fuzzy evaluation allocation method given by experts, is inevitably subjective ${ }^{[5]}$.AHP, a combination of quantitative and qualitative, can reduce shortcomings caused by personal subjective assumptions and make the evaluation results more credible ${ }^{[6]}$.

According to the membership degree theory of fuzzy mathematics, a multistage fuzzy evaluation assignment method $^{[7]}$ transforms qualitative evaluation into quantitative evaluation. Fuzzy mathematics is used to make a quantitative evaluation of various systems restricted by numerous factors, and then to determine the relative proportion of reliability between subsystems. In determining the weight of influencing factors, experts directly score according to the scoring rules, which are subjective and blind, and lack of corresponding reference $^{[8]}$.

Considering the inefficiencies above, this paper puts forward an improved multi-level fuzzy evaluation allocation method. The core of this method is to introduce the improved AHP method to determine the weight of factors, and the Fuzzy evaluation allocation method is used for comprehensive evaluation. The new method is applied to the allocation of the reliability index of aircraft engines.

\section{The Multistage Fuzzy Evaluation Assignment METHOD}

\section{A. The Establishment of Factors Affecting Reliability}

For the reliability allocation of complex systems, the multilevel fuzzy comprehensive evaluation allocation method[9] takes into account the fuzziness of the influencing factors, and the different levels of the influencing factors. There are a number of factors affecting the reliability of complex systems, such as technical level, complexity, importance, working hours, working environment, cost, weight, size, etc. The influence degree of each factor on the system is different. According to principle of objectivity, scientificity, integrity and validity, the influence factors are divided into layers. Therefore, the first level factor set $U_{i}(i=1,2, \cdots, n)$ consist of $\mathrm{n}$ subset of factors. Therefore, the first level factor set $\mathrm{U}$ consists of $\mathrm{n}$ factor subsets. The second factor subset also contains $m$ factors.

$$
\begin{gathered}
U=\left\{U_{1}, U_{2}, \cdots, U_{n}\right\} \\
U_{i}=\left\{u_{i 1}, u_{i 2}, \cdots, u_{i s}\right\}
\end{gathered}
$$

The number of subsets of each factor can be different, but conditions must be met.

$$
\begin{aligned}
& \bigcup_{\mathrm{i}=1}^{\mathrm{m}} U_{i}=U \\
& U_{i} \cap U_{\mathrm{j}}=\varnothing,(\mathrm{i} \neq \mathrm{j})
\end{aligned}
$$

\section{B. Establishment of Factor Evaluation Set and} Corresponding Value Set.

According to the actual situation and reliability requirements of the distribution object, a factor evaluation grade set is established. Size, length and quality of the elements in factor sets can be expressed by "lower, low, general, high, higher" or "worse, bad, general, good, better" and so on. The $\mathrm{m}$ evaluation levels for the subset of factors are shown in table 1. The set of States is the factor evaluation level set $V_{i j}$.

$$
V_{i j}=\left(v_{i j 1}, v_{i j 2}, \cdots, v_{i j p}\right) \quad(m=1,2 \cdots, p)
$$


TABLE I. T FACTOR EVALUATION SET

\begin{tabular}{|c|c|c|c|c|c|}
\hline $\begin{array}{c}\text { factor } \\
\text { evaluation set }\end{array}$ & $v_{i j 1}$ & $v_{i j 2}$ & $v_{i j 3}$ & $v_{i j 4}$ & $v_{i j 5}$ \\
\hline \multirow[t]{2}{*}{ technical level } & low & 1 & gener & $\mathrm{h}$ & hig \\
\hline & er & ow & al & igh & her \\
\hline \multirow[t]{2}{*}{ work environment } & wor & $\mathrm{b}$ & general & $\mathrm{g}$ & bett \\
\hline & se & $\mathrm{ad}$ & & ood & er \\
\hline
\end{tabular}

$$
C=\left(c_{1}, c_{2}, \cdots, c_{p}\right)
$$

$c_{m}$ represents the relative value of the reliability assigned by the $\mathrm{m}$ level. The higher the value of $c_{m}$, the higher the degree of resistance is assigned to it.

\section{The Establishment of Factors Affecting Reliability.}

Weights represent the influence of various factors on the system reliability level.The weight reflects the position and function of each factor in the comprehensive decision, and directly influences the result of decision. $\mathrm{W}_{\mathrm{k}}$ is the weight of factor set $U$ of unit $k$. $W_{k i}$ is the weight of factor subset $U_{i}$ of unit $\mathrm{k}$.

$$
W_{k}=\left\{w_{1}, w_{2}, \cdots, w_{n}\right\}
$$

The factor subset weight set $\mathrm{W}_{\mathrm{ki}}$ is:

$$
W_{k i}=\left\{w_{i 1}, w_{i 2}, \cdots, w_{i n}\right\}
$$

$\mathrm{i}$ indicates the number of factor subset. The expert scoring method is usually used to determine the weight. As shown in table 2, $\mathrm{a}_{\mathrm{ksj}}$ denotes estimated value of the $\mathrm{j}$-th factor of the $\mathrm{k}$-th unit by expert $\mathrm{s}$. weight $\mathrm{W}_{\mathrm{k}}$ of factor set is obtained by taking average of $h$ estimated value of each factor and then normalizing the average.

$a_{k s j l}$ denotes estimated value of the 1-th factor of the $j$-th factor set of the k-th unit by the s-th expert. weight $\mathrm{W}_{\mathrm{k}}$ of factor subset is obtained by taking average of $h$ estimated value of each factor and then normalizing the average.

When normalizing, conditions must be met:

\begin{tabular}{|c|c|c|c|c|c|c|c|c|}
\hline & \multicolumn{3}{|c|}{$\mathbf{U}_{1}$} & \multicolumn{2}{|c|}{$\mathbf{U}_{2}$} & $\ldots$ & \multicolumn{2}{|c|}{$\mathbf{U}_{\mathbf{n}}$} \\
\hline & & $w_{k 11}$ & & $w_{l}$ & & & & \\
\hline \multirow[t]{4}{*}{$\vdots$} & & $\vdots$ & & & $\vdots$ & & & \\
\hline & & $w_{k h 1}$ & & $w_{k}$ & & & & \\
\hline & $u_{11}$ & $u_{12}$ & $u_{13}$ & $u_{21}$ & $\mathrm{u}_{22}$ & & $\mathrm{u}_{\mathrm{n} 1}$ & $\mathrm{u}_{\mathrm{n} 2}$ \\
\hline & $a_{k 111}$ & $a_{k 112}$ & $a_{k 113}$ & $a_{k 121}$ & & & & \\
\hline$\vdots$ & $\vdots$ & $\vdots$ & $\vdots$ & $\vdots$ & & & & \\
\hline & $a_{k h 11}$ & $a_{k h 12}$ & $a_{k h 1}$ & $a_{k h 21}$ & & & & \\
\hline
\end{tabular}

$$
\sum_{j=1}^{n} w_{i j}=1\left(w_{i j} \geq 0\right), \sum_{i=1}^{n} w_{i}=1\left(w_{i j} \geq 0\right) \text {. }
$$

TABLE II. EXPERT WEIGHT SCORING TABLE

\section{Multilevel Fuzzy Evaluation Model}

The comprehensive evaluation model is divided based on the level of influence reliability factors. If the influence factors are all at the same level, they are called one stage comprehensive evaluation. According to the method of factor hierarchy dividing, the hierarchical fuzzy evaluation model is divided into two levels. The first level synthetic evaluation reflects the correlation between the factor subset and the reliability assignment object. The secondary level synthetic evaluation reflects the correlation between the factor set and the reliability assignment object.

\section{(1) The first level fuzzy evaluation}

The expert evaluates each factor in the factor subset and then integrates all the factors in the subset. $r_{i j m}$ represents the evaluation of the $\mathrm{j}$-th factor $\mathrm{u}_{\mathrm{ij}}$ of the of the $\mathrm{i}$-th factor subset. Subordinated to the $\mathrm{m}$-th level $\mathrm{v}_{\mathrm{ijm}}$ in the evaluation level, the membership value of the evaluation object is $r_{i j m}(i=$ $1,2, \cdots, \mathrm{n} ; \mathrm{j}=1,2, \cdots, \mathrm{s} ; \mathrm{m}=1,2, \cdots, \mathrm{p})$. The evaluation matrix $\mathrm{R}_{\mathrm{ki}}$ of the $\mathrm{k}$-th element of the $\mathrm{k}$-th unit is established.

$$
R_{k i}=\left[\begin{array}{cccc}
r_{i 11} r_{i 12} & \cdots & r_{i 1 p} \\
r_{i 21} r_{i 22} & \cdots & r_{i 2 p} \\
\vdots & \vdots & \ddots & \vdots \\
r_{i s 1} & r_{i s 2} & \cdots & r_{i s p}
\end{array}\right]
$$

According to table 3 and the influence factors connotation, a number of experts compare each evaluation object to to get the evaluation matrix $R_{\mathrm{k} i}$. The expert makes a binary judgment that belongs to or does not belong to p levels and draws " $\sqrt{ }$ " on the corresponding space. The number of " $\sqrt{ }$ " in each box is counted and divided by the number of experts. The evaluation matrix $R_{\mathrm{k} i}$ is constructed in the order shown in table 3 .

TABLE III. FACTOR EVALUATION TABLE

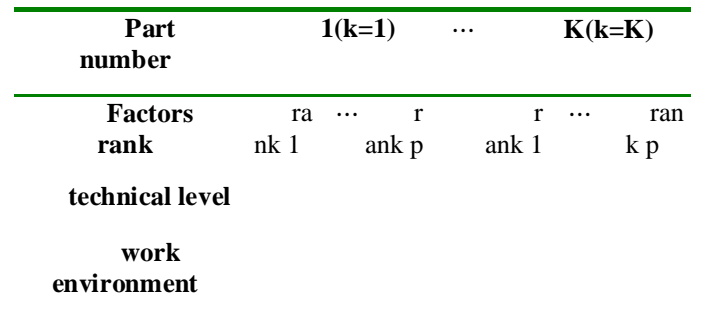

The fuzzy evaluation set of the ith factor subset and the kth component obtained by the fuzzy transformation:

$$
\begin{gathered}
B_{k i}=W_{k i}^{\circ} R_{k i}= \\
\left(w_{i 1}, w_{i 2}, \cdots, w_{i n}\right)^{\circ}\left[\begin{array}{cccc}
r_{i 11} r_{i 12} & \cdots & r_{i 1 p} \\
r_{i 21} r_{i 22} & \cdots & r_{i 2 p} \\
\vdots & \vdots & \ddots & \vdots \\
r_{i s 1} r_{i s 2} & \cdots & r_{i s p}
\end{array}\right]= \\
\left(b_{i 1}, b_{i 2}, \cdots, b_{i p}\right)
\end{gathered}
$$

In the formula, the symbol "。" is a fuzzy operator. In order to retain all the useful information as much as possible, the real 
number of addition and multiplication $\mathrm{M}(\cdot,+)$ is used to calculate:

$$
b_{i j}=\sum_{j=1}^{s} w_{i j} r_{i j m}
$$

Matrix $R_{k}$ is made up of of elements of $b_{\text {in }}$ :

$$
R_{k}=\left[\begin{array}{c}
B_{k 1} \\
B_{k 2} \\
\vdots \\
B_{k p}
\end{array}\right]=\left[\begin{array}{cccc}
b_{11} & b_{12} & \cdots & b_{1 p} \\
b_{21} & b_{22} & \cdots & b_{2 p} \\
\vdots & \vdots & \ddots & \vdots \\
b_{k 1} & b_{k 2} & \cdots & b_{k p}
\end{array}\right]
$$

$\mathrm{R}_{\mathrm{k}}$ is the grade comprehensive evaluation matrix, that is, the first level fuzzy evaluation matrix.

(2) The secondary level fuzzy evaluation

The matrix $B_{k}$ can be used as a single factor matrix for two-level fuzzy evaluation. Two-level fuzzy evaluation set:

$$
\begin{gathered}
B_{k}=W_{k}^{\circ} R_{k}=\left(w_{1}, w_{2}, \cdots, w_{n}\right)^{\circ}\left[\begin{array}{cccc}
b_{11} & b_{12} & \cdots & b_{1 n} \\
b_{21} & b_{22} & \cdots & b_{2 n} \\
\vdots & \vdots & \ddots & \vdots \\
b_{k 1} & b_{k 2} & \cdots & b_{k n}
\end{array}\right]= \\
\left(b_{1}, b_{2}, \cdots, b_{n}\right)
\end{gathered}
$$

(3) The secondary level fuzzy evaluation

The comprehensive evaluation score of the system could be obtained by multiplying The comprehensive evaluation matrix $B$ with the evaluation score set $\mathrm{C}$.

$$
d_{k}=B_{k} \cdot C^{T}
$$

\section{E. System Reliability Index Assignment}

Most mechanical systems are connected in series. When any part of the system fails, it will cause the whole system to fail. Assuming that the series system consists of $\mathrm{k}$ components and the reliability index value is $\mathrm{R}_{\mathrm{s}}^{*}{ }^{[10]}$. The above mentioned multi-level fuzzy comprehensive evaluation of $\mathrm{k}$ components is carried out to obtain the comprehensive evaluation score $d_{k}$ of the corresponding parts. The reliability of $\mathrm{K}$ parts is $\mathrm{R}_{\mathrm{k}}$ :

$$
R_{k}=R_{s}^{*} d_{k} / \sum_{k=1}^{K} d_{k}
$$

\section{The Weight OF FACTORS DETERMINED BY HIERARCHICAL DISTRIBUTION METHOD}

In the expert scoring method, whether the expert scores the factor directly according to the scoring rule or the fuzzy number introduced in the score has certain subjectivity and blindness, and lacks the mutual reference between the factor and the factor.

The weight vector is determined using an improved analytic hierarchy process ${ }^{[11,12]}$. The method overcomes the strong subjectivity of expert direct scoring method, lack of mutual comparison, uncertainty in ranking process of general scale importance and the complexity consistency test. This method is simple and clear. The concrete steps are as follows:
(1)Using the three scale method to establish complementary fuzzy judgment matrix $\mathrm{F}$ :

$$
F=\left(f_{i j}\right)_{m \times n}= \begin{cases}0 & A>B \\ 0.5 & A=B \\ 1 & A<B\end{cases}
$$

A represents the corresponding index of line i, B represents the corresponding index of column $\mathrm{j}$, and $\mathrm{n}$ represents the number of elements in the criterion layer.

(2)The fuzzy judgment matrix $\mathrm{F}$ is transformed into fuzzy consistent judgment matrix $Q \cdot q_{i}=\sum_{j=1}^{n} f_{i j}$ is given to Sum the data in lines and the transformation formula is used to obtain Q.

$$
q_{i j}=\frac{q_{i}-q_{j}}{2 n}+\frac{1}{2}
$$

The fuzzy consistency judgment matrix is obtained:

$$
Q=\left(q_{i j}\right)_{n \times n}
$$

(3) The weighting vector using sum and normalization method. The sum of the elements of each row (excluding identity comparison) of the fuzzy consistent matrix $Q=$ $\left(\mathrm{q}_{\mathrm{ij}}\right)_{\mathrm{n} \times \mathrm{n}}$ and the sum of the elements of the fuzzy consistent matrix $Q=\left(q_{i j}\right)_{n \times n}$ without diagonal elements are as follows:

$$
\begin{gathered}
l_{i}=\sum_{j=1}^{n} q_{i j}-0.5 \\
\sum_{i=1}^{n} l_{i}=n(n-1) / 2
\end{gathered}
$$

Since $l_{i}$ indicates the importance of the index i relative to the upper level target, the weights of each index can be obtained by normalization of $l_{i}$.

$$
w=\frac{l_{i}}{\sum_{i=1}^{n} l_{i}}=\frac{2 l_{i}}{n(n-1)}
$$

Weights of factor set are obtained:

$$
\mathrm{W}_{\mathrm{k}}=\left(\mathrm{w}_{1}, \mathrm{w}_{2}, \cdots, \mathrm{w}_{\mathrm{n}}\right)
$$

Similarly, weights of factor subset are obtained:

$$
\mathrm{W}_{\mathrm{ki}}=\left(\mathrm{w}_{\mathrm{i} 1}, \mathrm{w}_{\mathrm{i} 2}, \cdots, \mathrm{w}_{\mathrm{in}}\right)
$$

\section{CASE STUdy}

With hundreds of thousands of parts inside, aero engine is a complex system of integrative technique of mechanics-electronic-hydraulics. In an aero-engine system, the host system works most ${ }^{[12,13]}$. According to the functional principle, the main system of an aero-engine is composed of an air inlet, a compressor, a combustor, a turbine and an exhaust nozzle. In the initial stage of reliability design, the reliability of the system assigned to the engine host $R_{s}^{*}=0.906$.The method mentioned above is used to assign the reliability to individual components. 
A. The Establishment of Factors Affecting Reliability

The reliability factor set is set up for aircraft engine host system, as shown in table 4 .

TABLE IV. HIERARCHICAL DIVISION OF INFLUENCE FACTORS OF AERO-ENGINE RELIABILITY

\begin{tabular}{|c|c|c|}
\hline \multicolumn{3}{|c|}{ influence factors of aero-engine reliability } \\
\hline first layer & & Second layer \\
\hline \multirow{2}{*}{$\begin{array}{l}\text { Technical } \\
\text { level } U_{1}\end{array}$} & $u_{11}$ & design level \\
\hline & $u_{1=}$ & manufacturing level \\
\hline \multirow[t]{2}{*}{$\begin{array}{l}\text { Importanc } \\
\text { e } U_{2}\end{array}$} & $u_{2}$ & $\begin{array}{l}\text { consequences caused by } \\
\text { failure }\end{array}$ \\
\hline & $u_{2:}$ & Loss caused by failure \\
\hline \multirow{3}{*}{$\begin{array}{l}\text { Complexit } \\
\text { y } U_{3}\end{array}$} & $u_{3}$ & the number of components \\
\hline & $u_{3}$ & $\begin{array}{l}\text { the ratio of standardized } \\
\text { parts }\end{array}$ \\
\hline & $u_{3:}$ & the difficulty of disassembly \\
\hline \multirow{2}{*}{$\begin{array}{c}\text { work } \\
\text { environment } U_{4}\end{array}$} & $u_{4}$ & Load change \\
\hline & $u_{4}$ & Working hours \\
\hline
\end{tabular}

The factor evaluation set of aero engine is established as shown in Table 5

TABLE V. INFLUENCE FACTORS AND GRADES

\begin{tabular}{|c|c|c|c|c|c|}
\hline $\begin{array}{c}\text { factor } \\
\text { evaluation set }\end{array}$ & $\begin{array}{l}\text { ran } \\
\mathbf{k} 1\end{array}$ & $\begin{array}{ll} & \text { ran } \\
\mathbf{k} 2 & \end{array}$ & $\begin{array}{ll} & \text { ran } \\
\mathbf{k} 3 & \\
\end{array}$ & $\begin{array}{ll} & \operatorname{ran} \\
\mathrm{k} 4 & 4\end{array}$ & $\begin{array}{ll} & \text { ran } \\
\text { k } 5 & \end{array}$ \\
\hline$V_{11}\left(u_{11}\right)$ & $\begin{array}{l}\text { low } \\
\text { er }\end{array}$ & low & $\begin{array}{c}\text { gen } \\
\text { eral }\end{array}$ & hig & $\begin{array}{l}\text { high } \\
\text { er }\end{array}$ \\
\hline$V_{12}\left(u_{12}\right)$ & $\begin{array}{l}\text { low } \\
\text { er }\end{array}$ & low & $\begin{array}{r}\text { gen } \\
\text { eral }\end{array}$ & hig & $\begin{array}{l}\text { high } \\
\text { er }\end{array}$ \\
\hline$V_{21}\left(u_{21}\right)$ & $\begin{array}{c}\text { less } \\
\text { seri } \\
\text { ous }\end{array}$ & $\begin{array}{l}\text { not } \\
\text { seri } \\
\text { ous }\end{array}$ & $\begin{array}{c}\text { gen } \\
\text { eral }\end{array}$ & $\begin{array}{l}\text { seri } \\
\text { ous }\end{array}$ & $\begin{array}{l}\text { Mor } \\
\mathrm{e} \\
\text { seri } \\
\text { ous }\end{array}$ \\
\hline$V_{22}\left(u_{22}\right)$ & \begin{tabular}{|c|}
$\mathrm{Sm}$ \\
aller
\end{tabular} & $\begin{array}{c}\mathrm{Sm} \\
\text { all }\end{array}$ & $\begin{array}{c}\text { gen } \\
\text { eral }\end{array}$ & $\mathrm{e}^{\operatorname{larg}}$ & $\begin{array}{c}\text { larg } \\
\text { er }\end{array}$ \\
\hline$V_{31}\left(u_{31}\right)$ & $\mathrm{e}^{\mathrm{mor}}$ & $\begin{array}{c}\text { ma } \\
\text { ny }\end{array}$ & $\begin{array}{c}\text { gen } \\
\text { eral }\end{array}$ & few & $\begin{array}{l}\text { few } \\
\text { er }\end{array}$ \\
\hline$V_{32}\left(u_{32}\right)$ & $\begin{array}{l}\text { low } \\
\text { er }\end{array}$ & low & $\begin{array}{c}\text { gen } \\
\text { eral }\end{array}$ & hig & $\begin{array}{c}\text { high } \\
\text { er }\end{array}$ \\
\hline$V_{33}\left(u_{33}\right)$ & $\begin{array}{l}\text { har } \\
\text { der }\end{array}$ & har & $\begin{array}{c}\text { gen } \\
\text { eral }\end{array}$ & $\mathrm{y}^{\text {eas }}$ & $\begin{array}{l}\text { easi } \\
\text { er }\end{array}$ \\
\hline $\begin{array}{c}V_{41} \\
\left(u_{41}\right)\end{array}$ & $\begin{array}{l}\text { gre } \\
\text { ater }\end{array}$ & $\begin{array}{l}\text { gre } \\
\text { at }\end{array}$ & $\begin{array}{l}\text { gen } \\
\text { eral }\end{array}$ & $\begin{array}{r}\mathrm{Sm} \\
\text { all }\end{array}$ & $\begin{array}{l}\text { Sma } \\
\text { ller }\end{array}$ \\
\hline$V_{42}\left(u_{42}\right)$ & $\begin{array}{l}\text { lon } \\
\text { ger }\end{array}$ & $\mathrm{g}^{\text {lon }}$ & $\begin{array}{l}\text { gen } \\
\text { eral }\end{array}$ & $\begin{array}{l}\text { sho } \\
\mathrm{rt}\end{array}$ & $\begin{array}{l}\text { shor } \\
\text { ter }\end{array}$ \\
\hline
\end{tabular}

Each level is given a corresponding score. The technical level "higher" which refers to the maturity of technology is recorded as "16(24)"."The technical level "high" is recorded as " 8( $\left(2^{3}\right)$ ". The technical level "general" is recorded as $" 4\left(2^{2}\right)$ ".The technical level "low" is recorded as "2 $\left(2^{1}\right) "$ ". The technical level "lower" is recorded as "1 $\left(2^{0}\right)$ ". Corresponding to the factor level set, the value set $\mathrm{C}$ is:

$$
C=\left(c_{1}, c_{2}, \cdots, c_{p}\right)=(1,2,4,8,16)
$$

\section{B. Establishment of Weight Set}

According to the precedence relation between the hierarchical structure model and the three scaling method, the influence of each factor of the criterion layer on the overall reliability allocation is compared. According to the expert evaluation results, the reliability relation of each component of the aero-engine main system is sorted out.

For air inlet: Technical level > working environment > complexity > importance

The priority relation matrix is shown in table 6 converted by the above relationship.

TABLE VI. FUZZY DECISION MATRIX OF INLET FACTOR SET

\begin{tabular}{|c|r|r|r|r|}
\hline $\begin{array}{c}\text { air } \\
\text { inlet }\end{array}$ & \multicolumn{1}{|c|}{$\mathbf{U}_{\mathbf{1}}$} & \multicolumn{1}{|c|}{$\mathbf{U}_{\mathbf{2}}$} & $\mathbf{U}_{\mathbf{3}}$ & $\mathbf{U}_{\mathbf{4}}$ \\
\hline $\mathbf{U}_{\mathbf{1}}$ & 0.5 & 1.0 & 1.0 & 1.0 \\
\hline $\mathbf{U}_{\mathbf{2}}$ & 0 & 0.5 & 0 & 0 \\
\hline $\mathbf{U}_{\mathbf{3}}$ & 0 & 1.0 & 0.5 & 0 \\
\hline $\mathbf{U}_{\mathbf{4}}$ & 0 & 1.0 & 1.0 & 0.5 \\
\hline
\end{tabular}

By the Eq. (15), the fuzzy judgment matrix of Table 6 can be transformed into fuzzy consistent matrix:

According to the data in table 6 , the sum of the rows is obtained:

$$
q_{1}=3.5 \quad q_{2}=0.5 \quad q_{3}=1.5 \quad q_{4}=2.5
$$

By the Eq. (15), the fuzzy judgment matrix of Table 6 can be transformed into fuzzy consistent matrix:

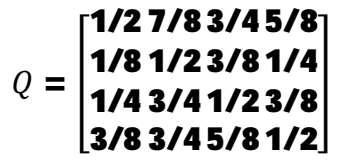

By the Eqs. (16),(17) and (18), the weight of air inlet factors set is calculated.

$$
\mathrm{W}_{1}=(0.3750,0.1250,0.2083,0.2917)
$$

By analogy, the influence of factor subset on inlet reliability is determined. According to the specific conditions of air inlet units and the expert experience, the following relative relation is obtained:

manufacturing level > design level

consequences caused by failure> Loss caused by failure

the ratio of standardized parts >the difficulty of disassembly $>$ the number of components

Load change $>$ working time

By reusing the step (1), (2) and (3) of improved AHP, Weights of factor subset affecting air inlet reliability are determined.

$$
W_{11}=(0.2500,0.7500), W_{12}=(0.7500,0.2500)
$$


$W_{13}=(0.1667,0.5000,0.3333)$

$W_{14}=(0.7500,0.2500)$
The factors set weights and factor subset weights of the compressor, combustion chamber, turbine and exhaust nozzle are obtained by repeating the above methods, as shown in table 7 .

TABLE VII. SUMMARY SHEET OF AIRCRAFT ENGINE HOST SYSTEM WEIGHTS

\begin{tabular}{|c|c|c|c|c|c|c|c|c|c|c|}
\hline & & \multicolumn{2}{|c|}{$\mathrm{U}_{1}$} & \multicolumn{2}{|c|}{$\mathbf{U}_{2}$} & \multicolumn{3}{|c|}{$\mathbf{U}_{3}$} & \multicolumn{2}{|c|}{$\mathbf{U}_{4}$} \\
\hline & & $\mathbf{u}_{11}$ & $\mathbf{u}_{12}$ & $\mathbf{u}_{21}$ & $\mathbf{u}_{22}$ & $\mathbf{u}_{31}$ & $\mathbf{u}_{32}$ & $\mathbf{u}_{33}$ & $\mathbf{u}_{41}$ & $\mathbf{u}_{42}$ \\
\hline \multirow[t]{2}{*}{ air inlet } & $W_{1 i}$ & 0.2500 & 0.7500 & 0.7500 & 0.2500 & 0.1667 & 0.5000 & 0.3333 & 0.7500 & 0.2500 \\
\hline & $\mathbf{W}_{1}$ & \multicolumn{2}{|c|}{0.3750} & \multicolumn{2}{|c|}{0.1250} & \multicolumn{3}{|c|}{0.2083} & \multicolumn{2}{|c|}{0.2917} \\
\hline \multirow[t]{2}{*}{ air compressor } & $\mathbf{W}_{2 \mathbf{i}}$ & 0.7500 & 0.2500 & 0.7500 & 0.2500 & 0.1667 & 0.3333 & 0.5000 & 0.2500 & 0.7500 \\
\hline & $\mathbf{W}_{2}$ & \multicolumn{2}{|c|}{0.3750} & \multicolumn{2}{|c|}{0.2083} & \multicolumn{3}{|c|}{0.2917} & \multicolumn{2}{|c|}{0.1250} \\
\hline \multirow[t]{2}{*}{ combustion } & $\mathbf{W}_{3 \mathbf{i}}$ & 0.7500 & 0.2500 & 0.7500 & 0.2500 & 0.1667 & 0.3333 & 0.5000 & 0.7500 & 0.2500 \\
\hline & $\mathbf{W}_{3}$ & \multicolumn{2}{|c|}{0.1250} & \multicolumn{2}{|c|}{0.3750} & \multicolumn{3}{|c|}{0.2083} & \multicolumn{2}{|c|}{0.2917} \\
\hline \multirow[t]{2}{*}{ turbine } & $\mathbf{W}_{4 i}$ & 0.2500 & 0.7500 & 0.7500 & 0.2500 & 0.1667 & 0.5000 & 0.3333 & 0.2500 & 0.7500 \\
\hline & $\mathrm{W}_{4}$ & \multicolumn{2}{|c|}{0.3750} & \multicolumn{2}{|c|}{0.2917} & \multicolumn{3}{|c|}{0.1250} & \multicolumn{2}{|c|}{0.2083} \\
\hline \multirow[t]{2}{*}{ exhaust nozzle } & $\mathbf{W}_{5 i}$ & 0.7500 & 0.2500 & 0.2500 & 0.7500 & 0.1667 & 0.3333 & 0.5000 & 0.7500 & 0.2500 \\
\hline & $\mathrm{W}_{5}$ & \multicolumn{2}{|c|}{0.3750} & \multicolumn{2}{|c|}{0.1250} & \multicolumn{3}{|c|}{0.2917} & \multicolumn{2}{|c|}{0.2083} \\
\hline
\end{tabular}

\section{The First Level Comprehensive Evaluation}

According to table 3, 10 aviation professionals make the first level synthetic evaluation of the reliability of the air inlet, as shown in table 8 .

\section{TABLE VIII. FUZZY EVALUATION TABLE OF INLET LEV}

\begin{tabular}{|c|c|c|c|c|c|c|}
\hline $\begin{array}{c}\text { air } \\
\text { inlet }\end{array}$ & $\begin{array}{l}\text { factor } \\
\text { set }\end{array}$ & nk1 ${ }^{\text {ra }}$ & $n k 2^{\text {ra }}$ & nk3 ${ }^{\text {ra }}$ & nk4 & $\mathrm{nk5}^{\mathrm{ra}}$ \\
\hline \multirow[t]{2}{*}{$\mathbf{U}_{\mathbf{1}}$} & $u_{11}$ & 0.3 & 0.6 & 0.1 & 0 & 0 \\
\hline & $\mathbf{u}_{12}$ & 0.1 & 0.2 & $\overline{0.4}$ & 0.3 & 0 \\
\hline \multirow[t]{2}{*}{$\mathbf{U}_{2}$} & $\mathbf{u}_{21}$ & 0 & 0.3 & 0.5 & 0.2 & 0 \\
\hline & $\mathbf{u}_{22}$ & 0 & 0 & 0.1 & 0.7 & 0.2 \\
\hline \multirow[t]{3}{*}{$\mathbf{U}_{3}$} & $\mathbf{u}_{31}$ & 0 & 0 & 0 & 0.4 & 0.6 \\
\hline & $\mathbf{u}_{32}$ & 0.1 & $\overline{0.4}$ & 0.3 & 0.2 & 0 \\
\hline & $\mathbf{u}_{33}$ & 0.5 & 0.4 & 0.1 & 0 & 0 \\
\hline \multirow[t]{2}{*}{$\mathbf{U}_{4}$} & $\mathbf{u}_{41}$ & 0 & 0.1 & 0.4 & 0.3 & 0.2 \\
\hline & $\mathbf{u}_{42}$ & 0.7 & 0.3 & 0 & 0 & 0 \\
\hline
\end{tabular}

According to table 8, the factor matrix of air inlet is obtained. Corresponding to the membership degree of each evaluation level, the factor set $\mathrm{U}_{1}$ constitutes the evaluation matrix $\mathrm{R}_{11}$. Similarly, $\mathrm{R}_{12}, \mathrm{R}_{13}$ and $\mathrm{R}_{14}$ are obtained.

$R_{11}=\left[\begin{array}{ccccc}0.3 & 0.6 & 0.1 & 0 & 0 \\ 0.1 & 0.2 & 0.4 & 0.3 & 0\end{array}\right] R_{12}=\left[\begin{array}{ccccc}0 & 0.3 & 0.5 & 0.2 & 0 \\ 0 & 0 & 0.1 & 0.7 & 0.2\end{array}\right]$

$R_{13}=\left[\begin{array}{ccccc}0 & 0 & 0 & 0.4 & 0.6 \\ 0.1 & 0.4 & 0.30 .2 & 0 \\ 0.5 & 0.4 & 0.1 & 0 & 0\end{array}\right] R_{14}=\left[\begin{array}{cccc}0 & 0.1 & 0.40 .30 .2 \\ 0.7 & 0 & 0.1 & 0.20 .5\end{array}\right]$

According to Eq.(9):

$B_{11}=(0.1500,0.3000,0.3250,0.2250,0)$
$B_{12}=(0,0.2250,0.4000,0.3250,0.0500)$

$B_{13}=(0.2167,0.3333,0.1833,0.1667,0.1000)$

$B_{14}=(0.1750,0.1500,0.3000,0.2250,0.1500)$

According to Eq.(10), $\mathrm{B}_{11}, \mathrm{~B}_{12}, \mathrm{~B}_{13}$ and $\mathrm{B}_{14}$ are used to form the first level synthetic evaluation matrix:

$\mathrm{R}_{1}=\left[\begin{array}{l}B_{11} \\ B_{12} \\ B_{13} \\ B_{14}\end{array}\right]=\left[\begin{array}{ccccc}0.1500 & 0.3000 & 0.3250 & 0.225 & 0 \\ 0 & 0.2250 & 0.4000 & 0.325 & 0.05 \\ 0.2167 & 0.3333 & 0.1833 & 0.1667 & 0.10 \\ 0.1750 & 0.1500 & 0.3000 & 0.2250 & 0.15\end{array}\right]$

Using the same method, the other parts of the host system, compressors, combustion chambers, turbines and nozzles are evaluated by experts, and then the first level synthetic evaluation matrix $R_{2} R_{3}, R_{4}, R_{5}$ are obtained.

\section{The Secondary Level Synthetic Judgment}

The secondary level fuzzy comprehensive evaluation is based on the first level evaluation, and uses the Eq. (11) to get the second class evaluation set of the five components of the host system.

$B_{1}=(0.1524,0.2538,0.2976,0.2253,0.0708)$

$B_{2}=(0.0569,0.1601,0.3806,0.3135,0.0608)$

$B_{3}=(0.1295,0.3517,0.2944,0.1847,0.0396)$

$B_{4}=(0.0115,0.1365,0.4948,0.2281,0.1292)$

$B_{5}=(0.0983,0.2017,0.2997,0.2938,0.1066)$

Finally, according to the Eq.(12), the comprehensive evaluation scores of each component are obtained.

$\mathrm{d}_{\text {air inlet }}=4.7865, \mathrm{~d}_{\text {compressor }}=5.3799, \mathrm{~d}_{\text {combustion }}=4.1219, \mathrm{~d}$ turbine $=6.1552, \mathrm{~d}_{\text {nozzle }}=5.7559$ 


\section{E. The Index Allocation of System Reliability}

The reliability index of aero-engine main engine system is assigned. When the reliability of the host system is $\mathrm{R}_{\mathrm{s}}^{*}=$ 0.906 , according to Eq.(13), the reliability of each part is :

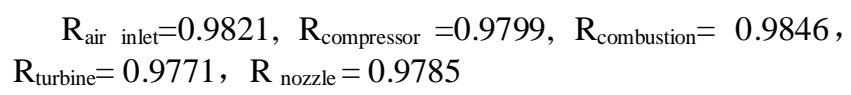

\section{CONCLUSION}

For the reliability allocation of complex mechanical system, not only the influence of various factors but also the hierarchy and fuzziness of the factors should be taken into account. The improved AHP was introduced to determine the weights of factors. The fuzzy evaluation method is used to synthetically evaluate the subset of factors. Combining qualitative and quantitative methods, the allocation model of aero-engine host system is established. The proposed method is suitable for engineering application at early stage of reliability design.

\section{REFERENCES}

[1] Mei Qizhi, Liao Jiongsheng, Sun Huizhong. Foundation of system reliability engineering [M] Beijing: Science Press, 2002.

[2] Guo Bo, Wu Xiaoyue. [M]. system reliability analysis Changsha: National University of Defense Technology press, 2002.

[3] Shao Yanfeng. Reliability allocation method for complex series and parallel systems [J]. aircraft design, 2007.2 (27): 51, 53.

[4] Huang Huang. Fuzzy method for reliability allocation of mechanical systems [J]. mechanical science and technology, 1996,15 (2): 182-186.

[5] Gu Yingkui, Wu Luheng. A Fuzzy AHP Approach to the Determination of W eights of Evaluation Factors in Mechanism Scheme Evaluation Process [J].China Mechanical Engineering,2007,18(9) : 1052-1055,1067.

[6] Peng Baohua, Zhao Jianyin, Sun Quan. Analytic hierarchy process for reliability apportionment of complex systems [J]. electronic product reliability and environmental testing, 2005 (6): 58-62.

[7] Liu Shan, Yao Gang. Multi-stage fuzzy evaluation of environmental impacts of highway construction projects [J]. Journal of Chang'an University (NATURAL SCIENCE EDITION), 2007,2 (1):11-12.

[8] Li Yong, Hu Xianghong, Qiao arrow. Improved fuzzy analytic hierarchy process [J]. Journal of Northwestern University (NATURAL SCIENCE EDITION), 2005, 2 (1):11-12.

[9] Buekley,JamesJ:Feuring,Thomas:Hayashi,Yoiehi.Fuzzy hierarchical analysis[J].IEEE Int Conf Fuzzy Syst.1999.5

[10] Zhao Dezi, Wen Weidong, Duan Michelle. Mechanical system reliability fuzzy allocation method of $[\mathrm{J}]$. mechanical science and technology, 2005, 24 (7):852-855.

[11] Park K S.Fuzzy apportionment of system reliability[J].IEEETransReliability.1987,36(2):129-132.

[12] Zhu Dexin, Liu Hongzhao. Reliability allocation of motorized spindle based on improved fuzzy analytic hierarchy process [J]. China Mechanical Engineering, 2011, 22 (24):2923-27.

[13] Xie Jing, Fan Wenzheng, Xie Xin. Evaluation of operational reliability of a military engine [J]. aero engines, 2012, 38 (6):43-47.

[14] reliability and economy of aero engines [M]. Beijing: National Defence Industry Press, 1998 